Int. J. Electrochem. Sci., 14 (2019) $7631-7642$

\title{
A Screen Printed Graphene Based Electrochemical Sensor for Single Drop Analysis of Hydroquinone in Cosmetic Products
}

\author{
Wannida Duekhuntod ${ }^{1}$, Chanpen Karuwan ${ }^{2}$, Adisorn Tuantranont ${ }^{2}$, Duangjai Nacapricha ${ }^{3,4}$ and \\ Saowapak Teerasong ${ }^{1,4, *}$
}

${ }^{1}$ Department of Chemistry and Applied Analytical Chemistry Research Unit, Faculty of Science, King Mongkut's Institute of Technology Ladkrabang, Bangkok 10520, Thailand

${ }^{2}$ National Electronics and Computer Technology Center, National Science and Technology

Development Agency (NSTDA), Pathumthani 12120, Thailand

${ }^{3}$ Department of Chemistry and Center of Excellence for Innovation in Chemistry,

Faculty of Science, Mahidol University, Bangkok 10400, Thailand

${ }^{4}$ Flow Innovative Research for Science and Technology Laboratories (FIRST Labs.)

*E-mail: saowapak.te@kmitl.ac.th

doi: $10.20964 / 2019.08 .94$

Received: 14 April 2019 / Accepted: 13 June 2019 / Published: 30 June 2019

A graphene modified carbon paste sensor (or so-called graphene based sensor) was developed for electrochemical detection of hydroquinone. The sensor was fast fabricated using screen-printing technique. By integrating three fundamental electrodes on a single device, the sensor is small and portable. A determination is based on a one drop analysis. A $60 \mu \mathrm{L}$-drop of sample was placed onto the sensor prior to cyclic voltammetric measurement. The method relies on green analysis since it lowers the consumption of sample and waste generation. Under the optimal conditions, a linear calibration was achieved in range of $1.0 \times 10^{-4}$ to $5.0 \times 10^{-3} \mathrm{M}$ hydroquinone. The detection limit was $7 \times 10^{-5} \mathrm{M}$, a sensitive adequate for measuring hydroquinone in cosmetic products. The sensor provided good precision $(\% \mathrm{RSD}=2.78)$ and accuracy (recoveries $=87-114 \%)$, with analysis times of less than a minute. The sensor was applied to determine the presence of hydroquinone in whitening creams. The results obtained from the developed sensor satisfactorily agreed with the HPLC method, indicating the reliability of the method. Due to its advantages in terms of rapidity, low-cost and portability, the device is a viable choice for on-site screening for hydroquinone contamination in whitening products.

Keywords: Electrochemical detection, Graphene, Hydroquinone, One drop analysis, Screen printing, Cosmetics

FULL TEXT 
(C) 2019 The Authors. Published by ESG (www.electrochemsci.org). This article is an open access article distributed under the terms and conditions of the Creative Commons Attribution license (http://creativecommons.org/licenses/by/4.0/). 